\title{
Rare case of paraurethral leiomyoma
}

\author{
Fahad Algreisi $^{1}$ *, Ahmad Ghazi ${ }^{1}$, Hattan Badr $^{2}$, Musarrat Batool $^{1}$
}

\author{
${ }^{1}$ Department of Gyne-Urology, King Abdullah Medical City, Makkah, The Holy Capital (KAMC-HC), Saudi Arabia \\ ${ }^{2}$ Department of Urology, King Abdullah Medical City, Makkah, The Holy Capital (KAMC-HC), Saudi Arabia
}

Received: 05 November 2016

Revised: 06 November 2016

Accepted: 09 November 2016

\author{
*Correspondence: \\ Dr. Fahad Algreisi, \\ E-mail: fahadalgreisi@yahoo.com
}

Copyright: () the author(s), publisher and licensee Medip Academy. This is an open-access article distributed under the terms of the Creative Commons Attribution Non-Commercial License, which permits unrestricted non-commercial use, distribution, and reproduction in any medium, provided the original work is properly cited.

\section{ABSTRACT}

A 35-year-old woman presented to our clinic with a mass in the left paraurethral area, slightly proximal to the urethra, that she had noticed 5 months before. The patient underwent urethrocystoscopy and had the mass excised. A histopathological examination led to a diagnosis of paraurethral leiomyoma.

Keywords: Leiomyoma, Paraurethral

\section{INTRODUCTION}

Leiomyomas are benign tumors that extend from smoothmuscle cells. They are the most common type of tumor in female reproductive organs, but rare outside the uterus. ${ }^{1}$ Only a few cases of paraurethral leiomyoma have been discussed in the literature.

\section{CASE REPORT}

A 35-year-old woman presented to our clinic with a mass in the left paraurethral area, slightly proximal to the urethra, that she had noticed 5 months before. It had gradually increased in size and became painful while sitting and working. She had no history of urinary complaints such as dysuria, hematuria or urine retention, and no trouble with bleeding or discharges from the mass. She was seen by urology and then referred to urogynecology because there was no urinary complaint, her urethra was not involved and she had no other co morbidity.

Her examination and evaluation revealed a mobile $3 \times 2$ $\mathrm{cm}$ mass located in the left paraurethral area. It was soft, smooth and non-fluctuant with tenderness on palpation and no sign of inflammation or edema. The routine labs conducted were all within the normal limits. An MRI showed a well-defined, rounded lesion $2 \mathrm{~cm}$ in the anterolateral distil vagina exhibiting heterogeneous enhancement and fluid restriction representing a skene$\mathrm{duct} / \mathrm{soft}$-tissue vaginal mass.

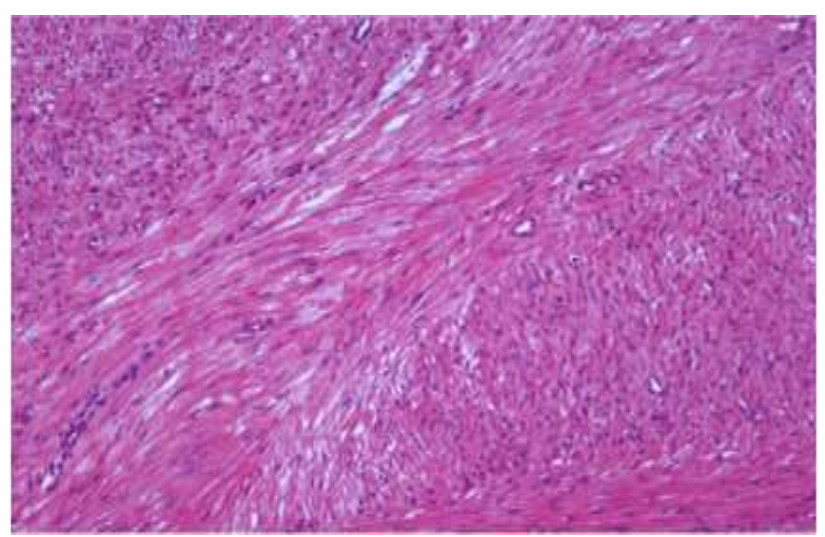

Figure 1: Hematoxylin and eosin stain X 10.

She was scheduled for an urethrocystoscopy and mass excision. Upon being admitted to the hospital, the mass 
was excised under general anesthesia and the results of the urethrocystoscopy were unremarkable. There was no communication between the mass and the urethra. A Foley was inserted and the mass was excised using a diamond-shaped incision. Once the mass was completely removed, the cavity was closed using a double-layer of vicryl 3/0. The Foley was removed at the end of procedure. The urethrocystoscopy was repeated with unremarkable results and the mass was sent for histopathology. The mass comprised smooth-muscle bundles arranged in a fascicular pattern and separated by vascularized connective tissue. In addition, a single segment of soft tissue covered by squamous epithelium was found to be consistent with leiomyoma.

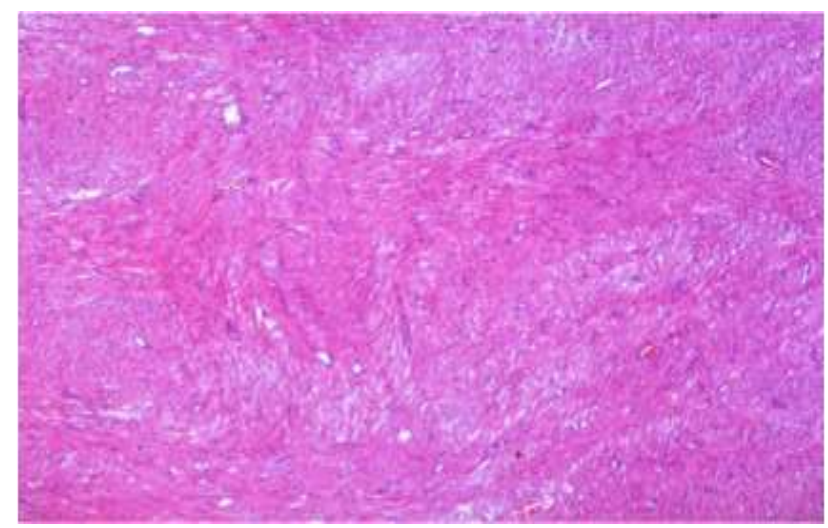

Figure 2: Hematoxylin and eosin stain X 4 .

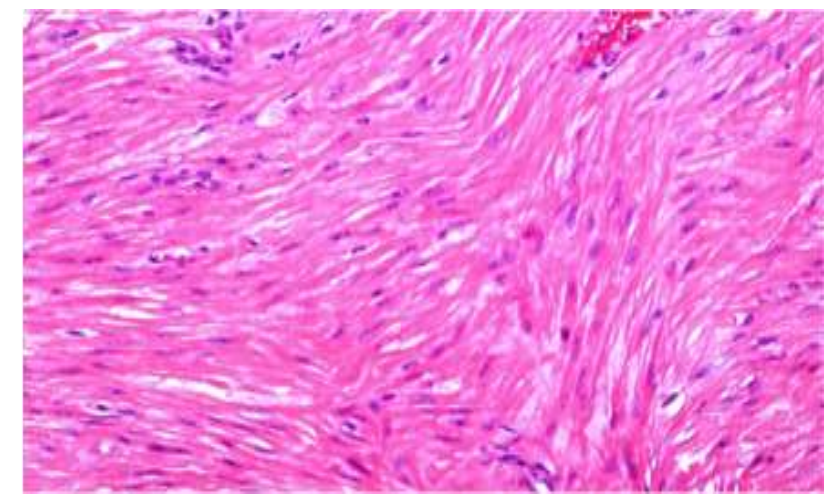

Figure 3: Hematoxylin and eosin stain X 20.

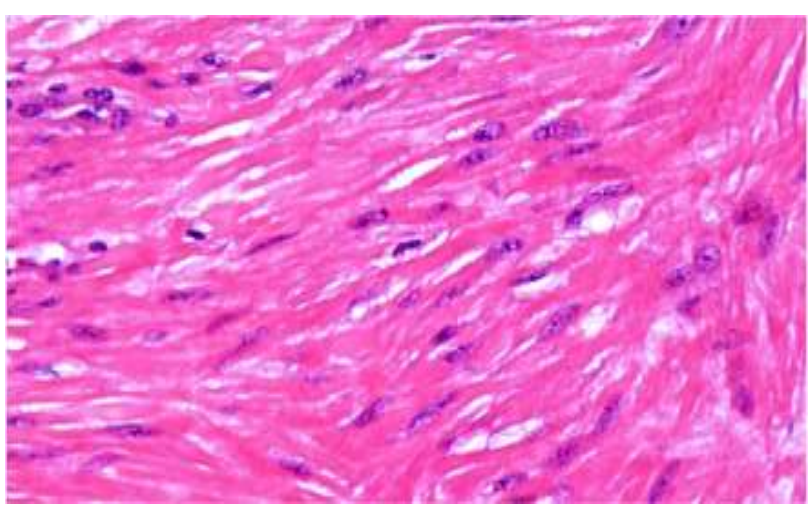

Figure 4: Hematoxylin and eosin stain X 40.
The patient followed up in OPD after six weeks and then returned to normal activity without any restrictions.

\section{DISCUSSION}

Paraurethral leiomyomas, which are, benign genitourinary tumors arising from smooth muscle, are exceedingly rare. Until recently, only six cases of paraurethral leiomyoma had been reported. ${ }^{1}$ The urethral (40) and vaginal (250) cases reported have all been welldocumented benign tumors. ${ }^{2,3}$ Paraurethral tumors occur in the paraurethral space or vesicovaginal septum and are mostly asymptomatic but are sometimes associated with pain, dyspareunia and voiding problems. ${ }^{4}$ Paraurethral tumors can clinically present as urethral and vaginal-wall leiomyoma because they grow in spaces that have no communication with the urethra, bladder or vagina., Differential diagnoses include urethral diverticulum, urethral mucosal prolapse, urethral caruncle, Bartholinn gland cyst, Gartner cyst, urethral carcinoma and vaginalwall cyst. $^{3,7,8}$

The ages of the patients in the 6 cases treated were between 32 and 49 years, and they were affected by paraurethral leiomyomas of different sizes. An MRI is the primary examination method used, followed by biopsy and complete surgical excision, with the latter most being the treatment of choice. ${ }^{9}$ The prognosis is typically excellent, as malignant transformations have not been reported and recurrences are rare. ${ }^{9,10}$ Paraurethral leiomyomas are considered non-recurring due to complete resection. Therefore, the excision of all suspected paraurethral leiomyomas is recommended through the anterior vaginal wall. ${ }^{10}$

Funding: No funding sources

Conflict of interest: None declared

Ethical approval: Not required

\section{REFERENCES}

1. Migliari R, Buffardi A, Mosso L. Female paraurethral leiomyoma: treatment and long-term follow-up. International Urogynecology Journal. 2015;26(12):1821-5.

2. Di Cello V, Saltutti C, Mincione GP, Rovereto B, Natali A, Durval A. Paraurethral leiomyoma in women. Eur Urol. 1988;15(3-4):290-3.

3. Sangwan K, Khosla AH, Hazra PC. Leiomyoma of the Vagina. Australian and New Zealand Journal of Obstetrics and Gynaecology. 1996;36(4):494-5.

4. Hubert KC, Remer EM, Rackley RR, Goldman HB. Clinical and magnetic resonance imaging characteristics of vaginal and paraurethral leiomyomas: can they be diagnosed before surgery? BJU Int. 2010;105(12):1686-8.

5. Selli C, Dal Canto M, Campani D, Bartoletti R, De Benedetto A. Leiomyoma of the female urethra. Urol Int. 1995;54(3):179-80. 
6. Cheng C, Mac-Moune Lai F, Chan PS. Leiomyoma of the female urethra: a case report and review. J Urol. 1992;148(5):1526-7.

7. Fry M, Wheeler JS, Mata JA, Culkin DJ, St Martin E, Venable DD. Leiomyoma of the female urethra. J Urol. 1988;140(3):613-4.

8. Cattolica EV, Klein R, Knigge W. Paraurethral leiomyoma-an imitator. Urology. 1976;8(6):605-7.
9. Migliari R, Buffardi A, Mosso L. Female paraurethral leiomyoma: treatment and long-term follow-up. Int Urogynecol J. 2015;26(12):1821-5..

10. Merrell RW, Brown HE. Recurrent urethral leiomyoma presenting as stress incontinence. Urology. 1981;17(6):588-9.

Cite this article as: Algreisi $\mathrm{F}$, Ghazi A, Badr H, Batool M. Rare case of paraurethral leiomyoma. Int J Reprod Contracept Obstet Gynecol 2016;5:4475-7. 